\title{
Acute ethanol administration induces oxidative changes in rat pancreatic tissue
}

\author{
E Altomare, I Grattagliano, G Vendemiale, V Palmieri, G Palasciano
}

\begin{abstract}
Background-There is mounting clinical evidence that ethanol toxicity to the pancreas is linked with glutathione depletion from oxidative stress but there is not experimental proof that this occurs. Aims and methods-The effect of acute ethanol ingestion $(4 \mathrm{~g} / \mathrm{kg})$ on the pancreatic content of reduced (GSH) and oxidised (GSSG) glutathione, malondialdehyde (MDA), and carbonyl proteins were therefore studied in the rat.

Results-Ethanol caused a significant reduction in GSH $(p<0.02)$ and an increase in GSSG $(\mathbf{p}<0.005)$, MDA $(p<0.05)$, and carbonyl proteins $(p<0.05)$ in the rat pancreas. The GSH/GSSG ratios were significantly decreased after ethanol, especially in rats pretreated with diethylmaleate (DEM), a GSH blocker. Administration of ethanol after DEM further increased the rate of lipid and protein oxidation. Pretreatment with cyanamide (an inhibitor of aldehyde dehydrogenase) but not with 4-methylpyrazole (an alcohol dehydrogenase inhibitor) caused higher production of GSSG and MDA.

Conclusions-These findings indicate that acute ethanol reduces the pancreatic content of GSH, which seems to be protective against ethanol toxicity, since its depletion is accompanied by increased oxidative damage to cell structures. The further increase of lipid peroxidation and GSSG production in the presence of cyanamide suggests that acetaldehyde might be responsible for the oxidative changes that occur in pancreatic cells after ethanol administration.

(Gut 1996; 38: 742-746)
\end{abstract}

Keywords: alcoholic pancreatic injury; glutathione; lipid peroxidation; protein oxidation.

There is growing evidence that exocrine pancreas is extremely vulnerable to damage from reactive oxygen species as well as metabolites of xenobiotics. ${ }^{12}$ In fact, pancreatic injury is a major cause of morbidity in the course of acute and chronic alcohol intoxication. ${ }^{34}$

Heightened free radical activity and increased levels of lipid peroxides have been documented in the serum and pancreatic tissue of patients with chronic alcoholic pancreatitis. ${ }^{56}$ These findings were also associated with changes in the glutathione and ascorbic acid redox status. Moreover, an imbalance in the sulphur amino acid metabolism, with decreased uptake of methionine by pancreatic cells and accumulation in plasma and leukocytes, has been observed in patients with chronic pancreatitis, ${ }^{7}$ probably as a result of a reduced transulphurative capacity. ${ }^{8}$

The influence of ethanol metabolism on pancreatic cells is of clinical interest. Besides the presence of pancreatic alcohol dehydrogenase activity, ${ }^{9} 10$ the reported induction of pancreatic cytochromes $\mathrm{P}-450$ in patients with chronic pancreatitis, including alcoholic pancreatitis, seems to be of great relevance because of the possible interaction between alcohol and drug metabolism and free radical production. ${ }^{11}$

The effects of ethanol intoxication can be counteracted by the antioxidant defence system, in which glutathione plays a fundamental role. ${ }^{12}$ In fact, recent clinical trials have shown that antioxidant supplementation may reduce the symptoms and oxidative stress in patients with chronic pancreatitis. ${ }^{13} 14$ Nevertheless, the molecular basis by which ethanol induces pancreatic oxidative changes and the role played by glutathione in the protection of pancreatic cells against ethanol toxicity are still not completely explained. This study aimed to investigate the effect of acute alcohol administration on rat pancreatic tissue in vivo. Evaluation of ethanol induced oxidative damage to lipids and proteins and changes in the glutathione redox status were also performed.

\section{Methods}

\section{EXPERIMENTAL PROCEDURE}

Male Sprague-Dawley rats weighing 180-200 $\mathrm{g}$ were studied. After overnight fasting they were given $25 \%$ ethanol ( $4 \mathrm{~g} / \mathrm{kg}$ body weight) or an isocaloric carbohydrate solution by stomach gavage. After six hours the rats were anaesthetised by intraperitoneal administration of sodium pentobarbital $(50 \mathrm{mg} / \mathrm{kg}$ ). The abdomen was opened and the pancreas quickly excised from other organ connections and trimmed of adipose tissue. Blood was collected in heparinised tubes by puncture of the inferior vena cava and was immediately centrifuged at $4000 \mathrm{~g}$ for three minutes. To study the protective role of glutathione against ethanol induced pancreatic toxicity, diethylmaleate (DEM: 250 $\mathrm{mg} / \mathrm{kg}$ of a $20 \%$ solution in corn oil), which can reduce glutathione concentrations without interfering with other metabolic pathways, ${ }^{15} 16$ was administered intraperitoneally one hour before ethanol or carbohydrate gavage.

To investigate the effect of ethanol and acetaldehyde metabolisms on biochemical 
changes in pancreatic tissue, some rats were treated intraperitoneally with 4-methylpyrazole $(75 \mathrm{mg} / \mathrm{kg}$ as a $0.2 \mathrm{M}$ saline solution, $\mathrm{pH}$ $7 \cdot 0),{ }^{10} 15$ an inhibitor of alcohol dehydrogenase $(\mathrm{ADH}), 30$ minutes before ethanol ${ }^{17}$ or sodium cyanamide $(50 \mathrm{mg} / \mathrm{kg}$ as a $0 \cdot 2 \%$ saline solution), ${ }^{18}$ a specific inhibitor of aldehyde dehydrogenase (ALDH), 60 minutes before ethanol.

Each study group included five to nine animals.

\section{GLUTATHIONE DETERMINATION}

Pancreatic specimens for total glutathione measurement were prepared by homogenising the samples in $10 \mathrm{vol}$ of $0.1 \mathrm{M}$ potassiumphosphate buffer $\mathrm{pH} 7 \cdot 4$ containing $5 \mathrm{mM}$ EDTA. The homogenates were then precipitated in $4 \%$ (wt/vol) sulphosalicylic acid and centrifuged for three minutes at $10000 \mathrm{~g}$ at $4^{\circ} \mathrm{C}$. The supernatant was analysed for glutathione by the glutathione-disulphide reductase 5,5-dithiobis (2-nitrobenzoic acid) recycling procedure. ${ }^{19}$ Results are expressed as $\mu \mathrm{mol}$ GSH/g pancreas.

Samples for oxidised glutathione (GSSG) assay were prepared by homogenising pancreatic specimens of approximately $50 \mathrm{mg}$ in $5 \mathrm{ml}$ of $10 \mathrm{mM}$ N-ethylmaleimide (NEM) solution in $100 \mathrm{mM}$ potassium-phosphate buffer and $17 \cdot 5 \mathrm{mM}$ EDTA pH 6.5. The homogenate was centrifuged at $3000 \mathrm{~g}$ for two minutes, and 1 $\mathrm{ml}$ was extracted with a $\mathrm{C}_{18}$ Sep-Pak cartridge (Waters Associates, Framinghan, MA) previously washed with methanol and water. ${ }^{20}$ The final eluate was then processed as reported above for glutathione determination. ${ }^{19}$ Reduced glutathione (GSH) values were determined by subtraction of GSSG from total glutathione. ${ }^{21}$

\section{DETERMINATION OF OXIDISED PROTEIN CONTENT}

Equal aliquots of homogenate samples (approximately $3 \mathrm{mg}$ of proteins) were precipitated with $10 \%$ (wt/vol) TCA and after centrifugation the pellet was treated with $1 \mathrm{ml}$ $0.2 \%$ (wt/vol) DNPH in $2 \mathrm{~N} \mathrm{HCl}$ or $1 \mathrm{ml}$ of $2 \mathrm{~N}$ $\mathrm{HCl}$ as a control blank. Samples were incubated for one hour at room temperature with five minute interval stirs. Next, $200 \mu \mathrm{l}$ of $50 \%$ TCA were added and the precipitated proteins were subsequently washed three time with $10 \%$ TCA, three times with $1: 1$ ( $\mathrm{vol} / \mathrm{vol})$ ethanol/ethylacetate, and three times again with $10 \%$ TCA. The final precipitate was dissolved in $6 \mathrm{M}$ guanidine hydrochloride titrated to $\mathrm{pH} 2.5$ with TCA: insoluble debris was removed by centrifugation. ${ }^{22}$ The different spectrum of the DNPH derivatives versus $\mathrm{HCl}$ controls was followed spectrophotometrically at $365-378 \mathrm{~nm} .^{23}$ The concentration of carbonyl groups was calculated from the spectrum absorbance, using $21.5 \mathrm{mM}^{-1} \mathrm{~cm}^{-1}$ as the extinction coefficient for aliphatic hydrazones. Results are expressed as nmol carbonyls per mg protein and are the mean of three sample determinations.
LIPID PEROXIDATION ASSAY

The measurement of malondialdehyde (MDA) was used to quantify the tissutal lipid peroxidation process. Pancreatic specimens of approximately $100 \mathrm{mg}$ were homogenised in $5 \mathrm{vol}$ of $180 \mathrm{mM} \mathrm{KCl}, 50 \mathrm{mM}$ Tris$/ \mathrm{HCl}, 10 \mathrm{mM}$ EDTA (pH 7.4) containing $0.02 \%$ (wt/vol) butylated hydroxytoluene to avoid spontaneous oxidation of unsaturated lipids; the homogenate was then precipitated with $10 \%$ (wt/vol) TCA and the resulting supernatant was incubated at $100^{\circ} \mathrm{C}$ for 45 minutes with an equal volume of $0.67 \%$ (wt/vol) thiobarbituric acid (TBA). After cooling, the supernatant was extracted with 1 $\mathrm{ml}$ of N-butanol; the peaks of absorption were visualised spectrophotometrically with a Scan program. MDA concentrations were then calculated using a standard curve of aqueous solutions of $1,1,5,5$-tetraethoxypropane. ${ }^{24}$

\section{HISTOLOGY}

After excision, small pancreatic fragments from each rat were immediately fixed in $10 \%$ formalin-phosphate buffer. The fixed tissues were embedded in paraffin; sections were stained with haematoxylin and eosin and then evaluated under light microscopy. Each sample was evaluated blindly. Damage to the cells was graded as cytoplasmatic vacuolisation, cytoplasmatic swelling, nuclear piknosis, or nuclear swelling. Indicators of more severe injury included hyperaemia, haemorrhage, and necrosis.

\section{PROTEIN CONTENT MEASUREMENTS}

Protein concentrations in plasma and pancreatic homogenate were measured by the method of Lowry. ${ }^{25}$ The protein concentration of the guanidine solved samples was assessed using a BIO-RAD kit for protein assay(BIO-RAD $\mathrm{GmbH}$, Munchen, Germany); bovine serum albumin, dissolved in guanidine, was used to prepare a standard curve.

\section{OTHER ASSAYS}

Serum amylase and lipase activities were determined using a standard method for automated analysis (Sigma).

\section{STATISTICAL ANALYSIS}

Data are expressed as mean (SEM). Differences were tested for statistical significance by the Student's $t$ test for unpaired data and one-way (ANOVA) analysis of variance. In all instances $p$ values of $<0.05$ were considered to be significant.

\section{Results}

The pancreas of ethanol treated rats seemed to be free of histological changes and plasma activities of amylase and lipase remained unchanged six hours after ethanol intake (amylase: $583.5(71.3)$ v 549.1 (155.3) UI/, NS; Lipase: $41 \cdot 3(13 \cdot 6) v 28 \cdot 4(12 \cdot 4) \mathrm{UI} / \mathrm{l}, \mathrm{NS})$. 
Figure 1: Reduced glutathione (GSH) content in the pancreas of six groups of rats. Groups $A$ and $B$ received orally $a$ carbohydrate solution or 4 g/kg ethanol, respectively. Groups $C$ and $D$ were injected intraperitoneally with 4-methylpyrazole or cyanamide respectively before ethanol ingestion. Groups $E$ and $F$ were given intraperitoneal diethylmaleate before carbohydrate or ethano ingestion, respectively. All animals were killed six hours after carbohydrate or ethanol ingestion. Each bar represents the mean (SEM) of five to nine experiments. ${ }^{\star} p<0.02$ and ${ }^{\star \star} p<0.005$ compared with $(A)$;

$\dagger p<0.01$ compared with (B) and $p<0.03$ compared with $(E)$.

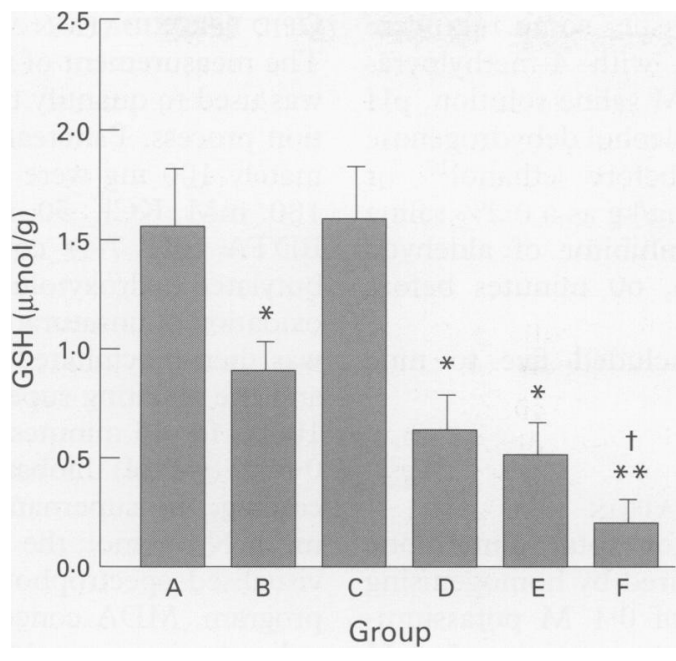

As shown in Figure 1, the pancreatic content of GSH was significantly decreased in rats acutely treated with alcohol compared with control animals $(0.91(0.11) \quad v 1.57(0.25)$ $\mu \mathrm{mol} / \mathrm{g}, \mathrm{p}<0.02)$. The fall in GSH values in ethanol treated rats was accompanied by an increased GSSG value $(0.118(0.022) v 0.046$ $(0.012) \mu \mathrm{mol} \mathrm{GSH} \mathrm{eq/g,} \mathrm{p<0.001)} \mathrm{(Fig} \mathrm{2).}$

In addition, the GSH/GSSG ratios were found to be significantly decreased in ethanol treated rats compared with control animals $(9.4(1.7) v 43.2(12 \cdot 4), \mathrm{p}<0.001)$.

Compared with the control group, animals taking alcohol showed an increase of the pancreatic content of oxidised proteins $(2.65$ $(0.36)$ v $1.98(0.27) \mathrm{nmol}$ carbonyls/mg protein, $\mathrm{p}<0.03$ ) (Fig 3) and of MDA-TBA reactive compounds $(4.93(1.01) v 2.77(0.58)$ $\mathrm{nmol} / \mathrm{g}, \mathrm{p}<0.009$ ) (Fig 4).

As shown in Figures 1-4, the inhibition of acetaldehyde metabolism, but not of ethanol, led to further significant changes in the GSH content and its redox status and of the lipid oxidation processes. As expected, the

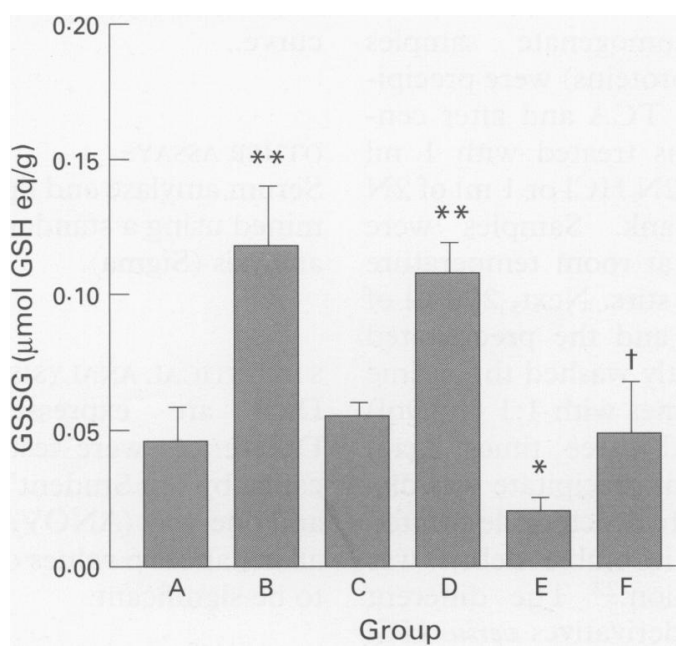

Figure 2: Oxidised glutathione (GSSG) concentrations in the rat pancreas six hours after oral administration of carbohydrate $(A)$ or $4 \mathrm{~g} / \mathrm{kg}$ ethanol $(B)$. Groups $C$ and $D$ were injected intraperitoneally with 4-methylpyrazole or cyanamide respectively before ethanol ingestion. Groups $E$ cyanamide respectively before ethanol ingestion. Groups carbohydrate or ethanol ingestion, respectively. Each bar represents the mean (SEM) of five to nine experiments. ${ }^{\star} p<0.01$ and ${ }^{\star \star} p<0.001$ compared with $(A) ;+p<0.01$ compared with $(E)$.

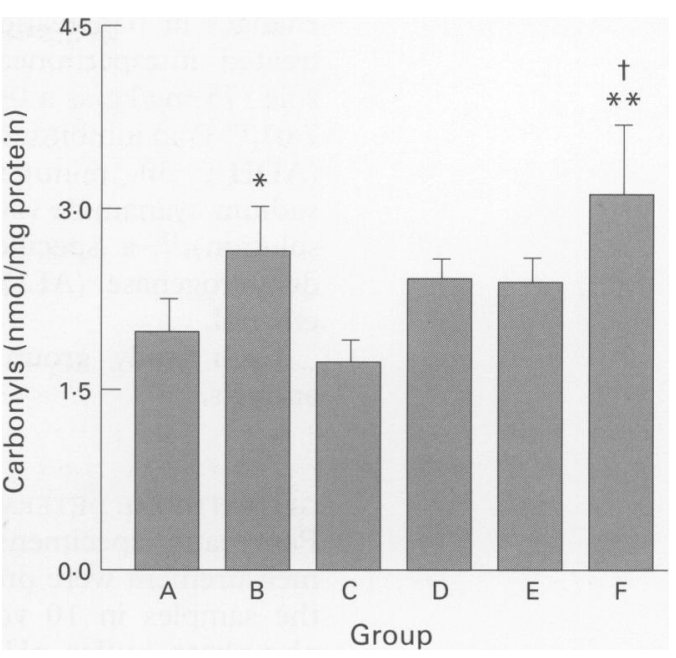

Figure 3: Carbonyl protein content in the pancreas of six groups of rats. Groups $A$ and $B$ received orally $a$ carbohydrate solution or $4 \mathrm{~g} / \mathrm{kg}$ ethanol, respectively. Groups $C$ and $D$ were injected intraperitoneally with 4-methylpyrazole or cyanamide respectively before ethanol ingestion. Groups $E$ and $F$ were given intraperitoneal diethylmaleate before carbohydrate or ethanol ingestion, respectively. All groups were killed six hours after carbohydrate or ethanol ingestion. Each bar indicates the mean (SEM) of five to nine experiments. ${ }^{\star} p<0.03$ and ${ }^{\star \star} p<0.02$ compared with $(A) ; \dagger p<0.03$ compared with (B) and $(E)$.

pancreatic content of GSH was significantly reduced by DEM $(0.53 \quad(0.13) \nu \mathrm{mol} / \mathrm{g}$, $\mathrm{p}<0.02$ compared with control rats. In addition, compared with rats which received ethanol alone, the administration of ethanol to DEM pretreated rats further reduced the levels of GSH $(0.20(0.09) v 0.91(0.11)$ $\mu \mathrm{mol} / \mathrm{g}, \mathrm{p}<0.01)$ and significantly increased MDA (6.36 (1.36) v $4.93(1.01) \quad \mathrm{nmol} / \mathrm{g}$, $\mathrm{p}<0.05)$ and carbonyl proteins $(3.12(0.56) v$ $2.65(0.36)$ nmol carbonyls/mg protein, $\mathrm{p}<0.03$ ) concentrations. The GSSG values were proportionally lowered in animals given

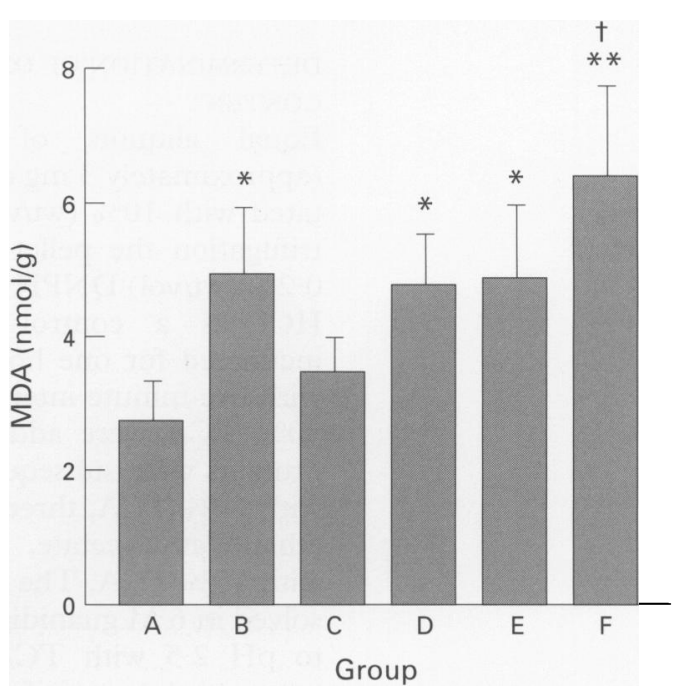

Figure 4: Malondialdehyde (MDA) content in the pancreas of six groups of rats. Groups $A$ and $B$ received orally a carbohydrate solution or $4 \mathrm{~g} / \mathrm{kg}$ ethanol, respectively. Groups $C$ and $D$ were injected intraperitoneally with 4-methylpyrazole or cyanamide, respectively before ethanol ingestion. Groups $E$ and $F$ were given intraperitoneal diethylmaleate before carbohydrate or ethanol ingestion, respectively. All groups were killed six hours after carbohydrate or ethanol ingestion. Each bar represents the mean (SEM) of five to nine experiments. ${ }^{\star} p<0.03$ and ${ }^{\star \star} p<0.01$ compared with $(A) ;+p<0.05$ compared with $(B)$ and $(E)$. 
DEM, so that the GSH/GSSG ratios remained unchanged. However, when ethanol was administered to DEM pretreated rats, the GSSG values increased significantly $(p<0.01)$ compared with rats given DEM alone, and the GSH/GSSG ratios were even lower than those in rats given only ethanol $(5 \cdot 1(2 \cdot 1) v 9 \cdot 4$ $(1 \cdot 7), p<0 \cdot 005)$. In the group of animals given ethanol and DEM, the plasma amylase activities were significantly higher six hours after ethanol administration (1526.7 (180.4) $\mathrm{U} / 1, \mathrm{p}<0.003$ compared with control rats), although only two rats showed slight histological neutrophil infiltration and cytosolic degranulation of the pancreas.

\section{Discussion}

Dramatic reductions in pancreatic GSH concentrations have been reported in animals affected by acute pancreatitis, ${ }^{26}$ in which free radical induced intracellular oxidative stress and enhanced release of lipid peroxidation products have been documented. ${ }^{27-29}$ Our data showed a reduction in the pancreatic GSH content accompanied by an increase in the GSSG concentration after acute administration of large amounts of alcohol. The increased concentrations of GSSG and the reduced GSH/GSSG ratios suggest an intracellular oxidative consumption of GSH. However, other mechanisms such as inhibition of GSH synthesis may play a contributory role. In fact, recent evidence of decreased utilisation of methionine and cysteine by pancreatic cells suggests an impairment of GSH synthesis in human pancreas after acute or acute on chronic pancreatitis. Increased concentrations of these sulph-hydryls were found in the plasma and urine of the same patients. ${ }^{730}$

An alternative, albeit unlikely, explanation for the reduction in pancreatic GSH is an inappropriate intracellular release of pancreatic digestive enzymes, whose secretion is partially inhibited by alcohol and which could be responsible for GSH degradation. GSH, however, is believed to be resistant to the action of intracellular peptidases. ${ }^{27}$

Our results also indicate that GSH depletion might exaggerate the effects of ethanol generated free radicals with consequent increases in lipid and protein oxidation rates. In fact, according to previous observations, ${ }^{31} \mathrm{GSH}$ depletion alone is not sufficient to produce histological signs of pancreatic injury, even if this facilitates the oxidation of cellular constituents. However, the protective effect of GSH against alcohol induced pancreatic injury is also clearly shown by its oxidative consumption in animals lacking GSH as a result of DEM treatment. In these animals enhanced oxidation of lipids and proteins together with an increase in plasma concentrations of amylase were observed. The absence of a histological evidence of tissue damage may be due to the early observation and prompted us to undertake further studies in our laboratories.

Since the loss of pancreatic GSH was more evident in animals in which the metabolism of acetaldehyde, but not of ethanol, was inhibited, our results strongly suggest that the reduction in pancreatic GSH is closely related to the toxic effects of ethanol metabolites. In fact, acetaldehyde has been shown to induce acute pancreatitis in isolated pancreas ${ }^{32}$ and could be responsible for the toxic effects in our in vivo model. Acetaldehyde may first react with small sulph-hydryls like GSH, contributing to their depletion, and next bind to important cellular structures. ${ }^{33}$ Furthermore, the induction of cytochrome $\mathrm{P}-450$ by chronic alcohol intake may exaggerate the toxic effect of ethanol on the pancreas by increasing the production of acetaldehyde which can subsequently form adducts with proteins and become chemoattractant for neutrophils. ${ }^{34}$

It is well documented that alcohol metabolism increases the production of malondialdehyde and other specific peroxides in pancreatic tissue and juice. ${ }^{15}$ The increase in lipid peroxidation products is commonly taken as an index of a change in membrane structure, ${ }^{35}$ and after acute alcohol ingestion, lipid peroxidation is detectable only after depletion of cellular GSH. ${ }^{36}$

The increased pancreatic concentrations of oxidised proteins after alcohol administration could be explained as a direct toxic effect of ethanol/acetaldehyde on the proteins or as a consequence of the loss of cellular antioxidants. Accumulation of oxidised proteins is associated with a reduction in specific activity and changes in the chemical and physical properties of enzymes. ${ }^{37}$ In addition, protein oxidation and subsequent precipitation might be important in conditions of decreased secretion of sulph-hydryls in the pancreatic juice, such as during chronic alcohol consumption.

In conclusion, this study shows that high dose ethanol induces oxidative changes in pancreatic cell constituents as a consequence of intracellular ethanol metabolism and that GSH seems to be protective against ethanol toxicity. Raised serum amylase activity and initial microscopic changes are noticed only after a marked reduction in GSH. Since no histological lesions have been documented in rats given ethanol alone, it seems that the oxidative changes in pancreatic cells together with oxidative consumption of GSH may be early indices of cellular damage and may be considered among the basic injuries that lead to alcohol induced pancreatitis.

1 Gut A, Shiel N, Kay PM, Segal I, Braganza JM. Heightened free radical activity in blacks with chronic pancreatitis at Johannesburg South Africa. Clin Chim Acta 1994; 230 . 189-99.

2 Gut A, Chaloner C, Shofield D, Braganza JM. Xenobiotic metabolism studies in Soweto blacks with alcoholic metabolism studies in Soweto blacks wit

3 Singh $M$, Simsek H. Ethanol and the Pancreas. Current Singh M, Simsek H. Ethanol and the Pancrea
status. Gastroenterology 1990; 58: 1051-62.

Ranson JH. Acute pancreatitis: pathogenesic outcome and treatment. Clin Gastroenterol 1984; 13: 843-63.

5 Braganza JM, Wickens DG, Cawood P, Dormandy TL. Lipid peroxidation (free radical oxidation) products in bile from patients with pancreatic disease. Lancet 1983; ii: 375-9.

6 Guyan PM, Uden S, Braganza JM. Heightened free radical activity in pancreatitis. Free Radical Biol Med 1990; 8: 347-54.

7 Martensson J, Bolin T. Sulfur amino acid metabolism in chronic relapsing pancreatitis. Am $\mathcal{f}$ Gastroenterol 1988; 81: 1179-84.

8 Roth E, Zoch G, Schultz F, Kramer J, Muhlbacher F, Hamilton G, et al. Amino acid concentrations in plasma 
and skeletal muscle of patients with acute hemorrhagic necrotizing pancreatitis. Clin Chem 1985; 31: 1305-9.

9 Hamamoto T, Yamada S, Hirayama C. Nonoxidative metabolism of ethanol in the pancreas; implication in alcoholic pancreatic damage. Biochem Pharmacol 1990; 39: 241-45.

10 Estival A, Clement F, Ribet A. Ethanol metabolism by rat pancreas. Toxicol Appl Pharmacol 1981; 61: 155-65.

11 Foster JR, Idle JR, Hardwick JP, Bars R, Scott P, Braganza JM. Induction of drug-metabolizing enzymes in human pancreatic cancer and chronic pancreatitis. $\Im$ Pathol 1993; pancreatic cance

12 Fernandez-Checa JC, Ookhtens M, Kaplowitz N. Effects of chronic ethanol-feeding on rat hepatocytic glutathione: compartmentation, efflux and response to incubation with ethanol. $\mathcal{f}$ Clin Invest 1987; 80: 57-62.

13 Uden S, Schofield D, Miller PF, Day JP, Bottiglieri T, Braganza JM. Antioxidant therapy for recurrent pancreatitis: biochemical profiles in a placebo-controlled trial. Alimentary Pharmacology Therapy 1992; 6: 229-40.

14 Uden S, Bilton D, Nathan L, Hunt LP, Main C, Braganza JM. Antioxidant therapy for recurrent pancreatitis: a placebo-controlled trial. Alimentary Pharmacology Therapy placebo-controlled

15 Robert A, Eberle N, Kaplowitz N. Role of glutathione in gastric mucosa cytoprotection. Am F Physiol 1984; 247: 296-304.

16 Kobayashi T, Robinson MK, Robinson V, DeRosa E, Wilmore DW, Jacobs DO. Glutathione depletion alters hepatocellular high-energy phosphate metabolism. f Surg Res 1993; 54: 189-95.

17 Feierman DE, Cederbaum CI. Increased content of cytochrome P-450 and 4-methylpyrazole binding spectrum after 4-methylpyrazole treatment. Biochem Biophys Res Commun 1984;126: 1076-81.

18 Deitrich RA, Troxell PA, Worth WS, Erwin VG. Inhibition of aldehyde deydrogenase in brain and liver by cyanamide. Biochem Pharmacol 1976; 25: 2733-7.

19 Tietze F. Enzymic method for quantitative determination of nanogram amounts of total and oxidized glutathione: applications to mammalian blood and other tissues. Anal Biochem 1969; 27: 502-22.

20 Adams JD, Lauterburg BH, Mitchell JR. Plasma glutathione and glutathione disulfide in the rat: regulation and response to oxidative stress. 7 Pharmacol Exp Ther 1983; 227: 749-54.

21 Schofield D, Mei G, Braganza JM. Some pitfalls in the measurement of blood glutathione. Clin Sci 1993; 85: measurem $213-8$.

22 Levine RL, Garland D, Oliver CN, Amici A, Climent I, Lenz A-G, et al. Determination of carbonyl content in oxidatively modified proteins. Methods Enzymol 1990; 186: 464-78.

23 Levine RL. Mixed-function oxidation of histidine residues. Methods Enzymol 1984; 107: 370-6.

24 Slater T, Sawyer B. The stimulatory effect of carbon tetrachloride and other halogenoalkanes on peroxidative reactions in rat liver fractions in vitro. Biochem $\mathcal{f} 1971 ; 123$ : 805-14.

25 Lowry OH, Rosenbrough NJ, Farr AL, Randall RJ. Protein measurement with the folin phenol reagent. F Biol Chem measurement with

26 Neuschwander-Tetri BA, Ferrell LD, Sukhabote RJ, Grendell JH. Glutathione monoethyl ester ameiliorates cerulein-induced pancreatitis in the mouse. $\mathcal{F}$ Clin Invest 1992; 89: 109-16.

27 Dabrowski A, Chwiecko M. Oxygen radicals mediate depletion of pancreatic sulfhydryl compounds in rats with cerulein-induced acute pancreatitis. Digestion 1990; 47: 15-9.

28 Schoemberg $M H$, Buchler M, Gaspar M, Stinner A, Younes M, Melzner I, et al. Oxygen free radicals in acute pancreatitis of the rat. Gut 1990; 31: 1138-43.

29 Sanfey H, Bulkley GB, Cameron JL. The pathogenesis of acute pancreatitis. The source and role of oxygen-derived acute pancreatitis. The source and role of oxygen-derived free radicals in three differ
Surg 1985; 201: 633-9.

30 Syrota A, Dop-Ngassa $M$, Cerf M, Faraf A. ${ }^{11} \mathrm{C}-\mathrm{L}-$ Methionine for evaluation of pancreatic exocrine function. Gut 1981; 22: 907-15.

31 Martensson J, Jain A, Meister A. Glutathione is required for intestinal function. Proc Natl Acad Sci USA 1990; 87: 1715-9.

32 Nordback IH, MacGowan S, Potter J, Cameron JL. The role of acetaldehyde in the pathogenesis of acute alcoholic pancreatitis. Ann Surg 1991; 214: 671-8.

33 Lauterburg BH, Bilzer M. Mechanisms of acetaldehyde hepatotoxicity. F Hepatol 1988; 7: 384-90.

34 Williams AJ, Barry RE. Superoxide anion production and degranulation of rat neutrophils in response to acetaldehyde-altered liver cell membranes. Clin Sci 1986; 71: 313-8.

35 Vendemiale G, Altomare E, Grattagliano I, Albano O. Increased levels of plasma glutathione and malondialdehyde after acute alcohol ingestion in humans. 7 Hepatol 1989; 9: 359-65.

36 Kera Y, Ohbora Y, Komura S. The metabolism of acetaldehyde and not acetaldehyde itself is responsible for in vivo ethanol-induced lipid peroxidation in rats. Biochem Pharmacol 1988; 37: 3633-8.

37 Stadtman ER. Protein oxidation and aging. Science 1992; 257: $1220-4$. 